\title{
Factors Associated with the Occurrence of Thyroid Nodules in Severely Obese Patients: A Case-Control Study
}

\author{
Raquel Andrade de Siqueira ${ }^{1 *}$, Matias Noll ${ }^{2,3}$, Ana Paula dos Santos Rodrigues ${ }^{3}$, \\ Erika Aparecida Silveira ${ }^{3 *}$
}

\begin{abstract}
Background: The association of obesity with the occurrence of thyroid nodules and thyroid cancer has been demonstrated. However, there is limited knowledge on the risk factors of thyroid nodules in in severely obese patients. The aim was to evaluate the occurrence of thyroid nodules in severely obese and nonobese patients and determine the factors associated considering sociodemographic, lifestyle, and biochemical variables. Methods: This is a case-control study of 134 adults which 67 nonobese, control group, and 67 severely obese (BMI $\geq 35 \mathrm{~kg} / \mathrm{m} 2$ ), case group. All participants underwent thyroid ultrasound. Results: The occurrence of thyroid nodules in a control group was $13.4 \%$ (n $=9$ ), while in a case group was $29.9 \%, n=20)$, difference statistically significant $(p=0.017)$. Factors associated with the occurrence of thyroid nodules in severely obese patients were lower mean age $(p=0.022)$; higher economic class $(p=0.010)$; nonconsumption of alcohol $(p=0.017)$; higher fasting glycemia $(p=0.009)$, fasting insulin $(p=0.001)$, homeostatic model assessment of insulin resistance [HOMA-IR] $(p=0.045)$, and triglyceride $(p=0.009)$ mean values; and lower vitamin $\mathrm{D}_{3}(\mathrm{p}=0.045)$ and high-density lipoprotein cholesterol $(\mathrm{p}=0.041)$ mean values. Conclusions: Occurrence of thyroid nodules in severely obese patients was higher than nonobese. Lower age at diagnosis, higher economic level, nonconsumption of alcohol, hyperinsulinemia, higher HOMA-IR scores, and lower vitamin $\mathrm{D}_{3}$ levels were factors associated with the occurrence of thyroid nodules in severely obese patients.
\end{abstract}

Keywords: Thyroid cancer- cancer- risk factors- HOMA-IR- vitamin D

Asian Pac J Cancer Prev, 20 (3), 693-697

\section{Introduction}

Thyroid nodules are a common clinical problem (Haugen et al., 2016). The prevalence of thyroid nodules evaluated by ultrasound is extremely high, reaching $68 \%$ of the general population (Guth et al., 2009; Tan and Gharib, 1997). Investigating thyroid nodules is important to evaluate malignancy risk (Hegedus, 2004). As the incidence of thyroid cancer has tripled in the last 30 years (Davies et al., 2015), proper investigation of thyroid nodules and associated factors is fundamental to define a better diagnostic approach.

The prevalence of obesity has alarmingly increased worldwide, especially in severely obese patients (BMI $\geq$ $35 \mathrm{~kg} / \mathrm{m}^{2}$ ) (NCD, 2016). Several studies consider obesity as an important risk factor for the occurrence of thyroid nodules and cancer (Davies et al., 2015; Lauby-Secretan et al., 2016; Pappa and ALevizaki, 2014; Rezzonico et al., 2008; Rezzonico et al., 2009). Endocrine and metabolic abnormalities among obese patients, such as hyperinsulinemia and common insulin resistance, can favor increased thyroid proliferation and tumorigenesis
(Lauby-Secretan et al., 2016; Pappa and ALevizaki, 2014; Rezzonico et al., 2008; Rezzonico et al., 2009). Therefore, severely obese patients may be more likely to develop thyroid nodules than nonobese individuals. However, few studies (Cappelli et al., 2012; Sousa et al., 2013) have investigated the presence of thyroid nodules and their associated factors in severely obese individuals.

Considering the scenario of pandemic severe obesity and the exponential increase in thyroid cancer incidence, investigating thyroid nodules and their associated factors is crucial to develop preventive measures and more appropriate approaches to thyroid nodular disease and increase scientific knowledge. Thus, this study aimed to evaluate the occurrence of thyroid nodules in severely obese and nonobese patients and determine the factors associated considering sociodemographic, lifestyle and biochemical variables.

\section{Materials and Methods}

Study design

This is a case-control study of adult residents in

${ }^{1}$ Department of Thyroid, Hospital Geral de Goiania (HGG), ${ }^{2}$ Instituto Federal Goiano, ${ }^{3}$ Programa de Pós-Graduacão em Ciências da Saúde, Faculdade de Medicina, Universidade Federal de Goiás (UFG), Brazil. *For Correspondence: raquel.a.siqueira@hotmail.com,erikasil@terra.com.br 
the metropolitan area of Goiânia, Goiás, Brazil, aged 18-65 years, who visited the Ambulatório de Nutrição em Obesidade Grave (ANOG, Nutrition Outpatient Clinic for Severe Obesity), Hospital das Clínicas (HC), Federal University of Goiás (UFG). The study was approved by the Research Ethics Committee (CEP no. 1.398.352) of HC-UFG. All participants signed the Informed Consent Form. This study is part of a larger research project called "Effect of Nutritional Intervention and Olive Oil in Severe Obesity" (DietBra Trial) (Rodrigues et al., 2018), which investigated 150 severely obese adults. Case data were randomly extracted from the larger study. Control data were collected from the same hospital, after recruitment in the orthopedics, dermatology, ophthalmology, and radiology outpatient clinics.

This study was designed in a 1:1 ratio. The case group included severely obese individuals $\left(B M I \geq 35 \mathrm{~kg} / \mathrm{m}^{2}\right)$; the control group, nonobese individuals (BMI $<30 \mathrm{~kg} / \mathrm{m}^{2}$ ). Subjects with thyroid nodular disease, previous bariatric surgery, and pregnancy were excluded from both groups.

\section{Data collection}

Data were collected from June 2015 to July 2016. Although case information was extracted from the larger study (Rodrigues et al., 2018), all case and control data collection procedures were uniformly conducted according to previously established procedures. Standardized pretested questionnaires were used to collect sociodemographic (age, sex, education, marital status, socioeconomic class) and lifestyle (smoking, alcohol consumption) data and assess thyroid cancer risk factors (use of iodized salt, exposure to ionizing radiation, family history of thyroid cancer). Data collection was conducted by a trained professional from the Department of Pathological Anatomy and Cytology of Goiânia.

Anthropometric measurements were performed. Weight was measured using a mechanical platform scale with a maximum capacity of $300 \mathrm{~kg}$ and a precision level of 100 grams. Height was measured using a stadiometer coupled to the mechanical scale, with a precision level of $0.1 \mathrm{~cm}$. The BMI was determined by dividing the weight in kilograms by height in meters squared [BMI $=$ weight $(\mathrm{kg}) /$ height $\left.(\mathrm{m})^{2}\right]$ (WHO, 2000). Cervical circumference (CC) was measured using the inelastic tape measure placed directly below the laryngeal prominence of the cricothyroid cartilage, perpendicular to the longitudinal axis of the neck, with the head positioned horizontally (Li et al., 2014).

Biochemical parameters included thyroid-stimulating hormone (TSH), free thyroxine (T4), total triiodothyronine (T3), anti-thyroperoxidase antibodies (ATPO), fasting glycemia (FG), fasting insulin (FI), homeostatic model assessment of insulin resistance (HOMA-IR), vitamin $\mathrm{D}_{3}$, total cholesterol, high-density lipoprotein (HDL), low-density lipoprotein (LDL), and triglyceride levels. HOMA-IR was calculated using the formula FG x 0.0555 $x \mathrm{FI} / 22.5$ and had a normal reference value of $\leq 3.4$. TSH, free T4, total T3, ATPO, FI, and vitamin $\mathrm{D}_{3}$ were measured by chemiluminescent microparticle immunoassay (Roche Diagnostics).

Ultrasound was performed in both groups at the
HC-UFG Radiology Center, with a maximum interval of 4 weeks between answering the questionnaire and collecting the abovementioned data. Individuals diagnosed with thyroid nodules were included in this study. The ultrasound evaluation was conducted by two trained physicians, one specialized in radiology and the other specialized in endocrinology, with more than 10 years' experience in clinical and ultrasound examination of the thyroid. GE Logiq P6 ultrasound imaging devices were used, with convex and linear multifrequency transducers (10-13 MHz) for morphological analysis (mode B) and Doppler evaluation. Focal lesions (nodules) were considered present only if their diameter was $\geq 3 \mathrm{~mm}$. Nodular characteristics were not considered in this study.

Cervical subcutaneous tissue thickness was measured in centimeters by ultrasound, at the level of the thyroid isthmus, with an appropriate amount of gel layer without pressure from the examiner and using only the transducer's weight (Ugur et al., 2011).

\section{Statistical analysis}

Data were described using mean \pm standard deviation, and absolute and relative frequencies. The association of occurrence of nodules between case and control patients was analyzed according to the investigated variables using the independent t-test and Fisher's exact test, considering a significance level of 5\%. Data were analyzed using Stata software (StataCorp, College Station, TX, USA).

\section{Results}

This case control study included 134 patients, case and control groups. From these, $62(92.54 \%)$ with a BMI of $\geq 40 \mathrm{~kg} / \mathrm{m}^{2}$ (class III obesity). The case group presented a higher occurrence of nodules $(29.9 \%, \mathrm{n}=20)$ than the control group $(13.4 \%, \mathrm{n}=9)(\mathrm{p}=0.017)$.

In patients with thyroid nodules $(\mathrm{n}=29), 100 \%$ were women, $96.6 \%(\mathrm{n}=28)$ used iodized salt, $100 \%$ were not exposed to ionizing radiation, and $96.6 \%(\mathrm{n}=28)$ had no family history of thyroid cancer. The occurrence of thyroid nodules in these patients was associated with lower mean age, higher economic class (A, B, and C), and nonconsumption of alcohol (Table 1).

Regarding cervical variables both were statistically associated with the occurrence of thyroid nodules (Table 2). Among the biochemical variables analyzed, higher mean values of fasting glycemia, fasting insulin, HOMA-IR, and triglycerides were associated with the occurrence of thyroid nodules in the case group. Lower mean values for vitamin $\mathrm{D}_{3}$ and HDL-c was statistically associated of nodules (Table 3).

\section{Discussion}

Our study is the first to compare the frequency of thyroid nodules and associated factors in such population with a control group, thus contributing to the elaboration of an appropriate management protocol for thyroid nodular disease in severe obesity. Furthermore, sociodemographic variables linked to severe obesity such as age, social class, and biochemical variables were associated with the 
Table 1. Frequency of Thyroid Nodules in Case and Control Patients, and Association with Sociodemographic and Lifestyle Variables, as Well as Risk Variables for Thyroid Cancer

\begin{tabular}{|c|c|c|c|c|}
\hline \multirow[t]{2}{*}{ Variables } & $\begin{array}{c}\text { Total } \\
\mathrm{N}=29\end{array}$ & $\begin{array}{l}\text { Control } \\
n=9\end{array}$ & $\begin{array}{c}\text { Case } \\
\mathrm{n}=20\end{array}$ & \multirow[t]{2}{*}{$\mathrm{p}$ value } \\
\hline & Mean \pm SD & Mean \pm SD & Mean \pm SD & \\
\hline Age (years) & $42.62 \pm 9.39$ & $48.4 \pm 10.3$ & $40.0 \pm 7.8$ & $0.022 *$ \\
\hline \multirow{2}{*}{$\begin{array}{l}\text { Schooling } \\
\text { (years) }\end{array}$} & $10 \pm 3.5$ & $11.7 \pm 4.4$ & $9.5 \pm 3.2$ & $0.195 \dagger$ \\
\hline & n $(\%)$ & $\mathrm{n}(\%)$ & n $(\%)$ & \\
\hline \multicolumn{4}{|l|}{ Sex } & - \\
\hline Female & $29(100)$ & $9(100)$ & $20(100)$ & \\
\hline Male & 0 & 0 & 0 & \\
\hline \multicolumn{4}{|c|}{ Lives with a partner } & $0.074 \dagger$ \\
\hline No & $12(41.4)$ & $6(66.7)$ & $6(30)$ & \\
\hline Yes & $17(58.6)$ & $3(33.3)$ & $14(70)$ & \\
\hline \multicolumn{4}{|c|}{ Socioeconomic class } & $0.010 \dagger$ \\
\hline $\mathrm{D}$ and $\mathrm{E}$ & $9(31)$ & $6(67.7)$ & $3(15)$ & \\
\hline $\mathrm{A}, \mathrm{B}$, and $\mathrm{C}$ & $20(69)$ & $3(33.3)$ & $17(85)$ & \\
\hline \multicolumn{4}{|l|}{ Smoking } & $0.412 \dagger$ \\
\hline No & $18(62.1)$ & $7(77.8)$ & $11(55)$ & \\
\hline Yes & $11(37.9)$ & $2(22.2)$ & $9(45)$ & \\
\hline \multicolumn{4}{|c|}{ Alcohol consumption } & $0.017 \dagger$ \\
\hline No & $20(69)$ & $9(100)$ & $11(55)$ & \\
\hline Yes & $9(31)$ & 0 & $9(45)$ & \\
\hline \multicolumn{4}{|c|}{ Use of iodized salt } & $1.000 \dagger$ \\
\hline No & $28(96.6)$ & 0 & $1(100)$ & \\
\hline Yes & $1(3.4)$ & $9(32.1)$ & $19(67.9)$ & \\
\hline \multicolumn{4}{|c|}{ Exposure to ionizing radiation } & - \\
\hline No & $29(100)$ & $9(31)$ & $20(69)$ & \\
\hline Yes & 0 & 0 & 0 & \\
\hline \multicolumn{4}{|c|}{ Family history of thyroid cancer } & $1.000 \dagger$ \\
\hline No & $28(96.6)$ & $9(32.1)$ & $19(67.9)$ & \\
\hline Yes & $1(3.4)$ & 0 & $1(100)$ & \\
\hline
\end{tabular}

Table 2. Frequency of Thyroid Nodules in Case and Control Patients, and association with Cervical Variables.

\begin{tabular}{lcccc}
\hline Variables & $\begin{array}{c}\text { Total } \\
\mathrm{N}=29\end{array}$ & $\begin{array}{c}\text { Control } \\
\mathrm{n}=9\end{array}$ & $\begin{array}{c}\text { Case } \\
\mathrm{n}=20\end{array}$ & $\begin{array}{c}\mathrm{p} \\
\text { value* }\end{array}$ \\
\hline $\begin{array}{l}\text { Cervical } \\
\text { circumference } \\
(\mathrm{cm})\end{array}$ & $37.7 \pm 8.65$ & $32.24 \pm 1.91$ & $38.2 \pm 2.71$ & 0.02 \\
$\begin{array}{l}\text { Thickness } \\
\text { of cervical } \\
\text { subcutaneous } \\
\text { tissue (cm) }\end{array}$ & $8.14 \pm 3.85$ & $3.77 \pm 1.63$ & $10.1 \pm 2.75$ & 0.001 \\
\hline *Independent t-test & & & & \\
\hline
\end{tabular}

*Independent t-test

occurrence of thyroid nodules.

Here, all case and control individuals with thyroid nodules were females, corroborating the higher occurrence of nodules in women in other studies (Papini et al., 2002; Kim et al., 2008). This suggests that females are more predisposed to having thyroid nodules. One hypothesis could be the increased role of estrogen and aromatase activity in women, as a mediating mechanism of thyroid proliferation (Pappa and Alevizaki, 2014). Another hypothesis could be the feminization of health, where women seek more medical care than men in basic health units (Figueiredo, 2005).

The mean age at nodule diagnosis was lower in obese patients (40 years), consistent with the findings of Cappelli et al., (2012). In control patients, the mean age was 48.4 years, similar to that observed by Papini et al., (47.8 years) (2002) and Kim et al., (2008) (49.2 years). A potential increasing role of obesity could be its involvement in mediating mechanisms of thyroid tumorigenesis, such as hyperinsulinemia, increased aromatase and leptin activity, chronic oxidative stress, impaired immune response, and chronic low-grade inflammation present in obese individuals, which favor early occurrence of thyroid nodules (Pappa and Alevizaki, 2014).

In this study, the presence of thyroid nodules in severely obese individuals was also associated with nonconsumption of alcohol. A positive association between total alcohol consumption and obesity was reported by Tolstrup et al., (2005). However, whether

Table 3. Frequency of Thyroid Nodules in Case and Control Patients, and association with Biochemical Variables

\begin{tabular}{lcccc}
\hline Variables & Total $\mathrm{N}=29$ & Control $\mathrm{n}=9$ & Case $\mathrm{n}=20$ & $\mathrm{p}$ value* \\
\hline TSH (mUI/L) & $2.92 \pm 1.73$ & $2.88 \pm 1.57$ & $2.94 \pm 1.84$ & 0.929 \\
Free T4 (ng/dL) & $1.20 \pm 0.16$ & $1.24 \pm 0.13$ & $1.18 \pm 0.18$ & 0.397 \\
Total T3 (ng/dL) & $1.29 \pm 0.31$ & $1.28 \pm 0.29$ & $1.30 \pm 0.33$ & 0.871 \\
Positive ATPO & $111.88 \pm 208.2$ & $125.8 \pm 197.2$ & $104.9 \pm 218.6$ & 0.805 \\
Fasting glycemia & $100.2 \pm 34.12$ & $82.44 \pm 7.3$ & $108.2 \pm 38.4$ & $\mathbf{0 . 0 0 9}$ \\
Fasting insulin & $15.1 \pm 8.75$ & $6.58 \pm 3.80$ & $18.9 \pm 7.51$ & $\mathbf{0 . 0 0 1}$ \\
HOMA-IR & $3.99 \pm 2.92$ & $1.39 \pm 0.94$ & $5.15 \pm 2.75$ & $\mathbf{0 . 0 4 5}$ \\
Vitamin D & $29.08 \pm 9.61$ & $34.35 \pm 10.8$ & $26.7 \pm 8.2$ & $\mathbf{0 . 0 4 5}$ \\
Total cholesterol & $186.45 \pm 35.9$ & $195.67 \pm 40.7$ & $182.3 \pm 33.8$ & 0.363 \\
HDL-c & $54.2 \pm 15.8$ & $63 \pm 20.05$ & $50.20 \pm 11.98$ & $\mathbf{0 . 0 4 1}$ \\
LDL-c & $103.6 \pm 32.2$ & $112.2 \pm 39.1$ & $99.75 \pm 28.8$ & 0.344 \\
Triglycerides & $140.4 \pm 68.2$ & $92.9 \pm 47.2$ & $161.8 \pm 8.21$ & $\mathbf{0 . 0 0 9}$ \\
\hline
\end{tabular}

*Independent t-test; TSH, thyroid-stimulating hormone; T4, thyroxine; T3, triiodothyronine; ATPO, anti-thyroperoxidase antibodies; HOMA-IR, homeostatic model assessment of insulin resistance; HDL-c, high-density lipoprotein cholesterol; LDL-c, low-density lipoprotein cholesterol. 
alcohol has a potentiating or protective effect on thyroid structures remains unknown.

Severely obese patients with thyroid nodules presented higher mean values cervical subcutaneous tissue thickness. A meta-analysis found a positive association between adiposity and thyroid cancer, corroborating our study results (Schmid et al., 2015). Although the connection between obesity and thyroid nodules is conflicting in the literature (Cappeli et al., 2012; Sousa et al., 2013), our study showed that the variables related to subcutaneous adiposity, cervical variables, were associated with a higher frequency of nodules. Moreover, a positive association between total body fat percentage and presence of thyroid nodules was verified in a cross-sectional study of 306 healthy individuals from northern Greece, which also agrees with our study findings (Panagiotou et al., 2017).

A positive association serum TSH elevation was confirmed by several researchers (Díez and Iglesias, 2011; Kitahara et al., 2012; Knudsen et al., 2005; Reinehr, 2011; Rotond et al., 2009; Solanki et al., 2013; Váldes et al, 2017), and recently, higher TSH concentrations were considered as an independent risk factor for thyroid nodules (Dauksiene et al., 2017). However, this study showed no significant difference in TSH values between severely obese and nonobese patients with nodules.

In this study, FG, FI, HOMA-IR, and triglyceride levels were higher and HDL levels were lower in severely obese patients with thyroid nodules. This altered metabolic profile, compatible with metabolic syndrome, is a common finding associated with increased cardiovascular risk in obesity (Poddar et al., 2017). However, whether these metabolic alterations independently favor the occurrence of thyroid nodules remains unclear (Rezzonico et al., 2008; Rezzonico et al., 2009; Sousa et al, 2013). Among these changes, insulin resistance stands out as a variable positively associated with nodules and thyroid cancer, independent of BMI (Rezzonico et al., 2008; Rezzonico et al., 2009).

This study also found lower vitamin $\mathrm{D}_{3}$ levels in severely obese individuals with thyroid nodules, which is consistent with the findings of other studies (Poddar et al., 2017; Savastano et al., 2017). Low sun exposure in obese individuals due to sedentary lifestyle with lower outdoor activity, vitamin D sequestration in adipose tissue, malabsorption, and accelerated catabolism can represent some of the factors associated with lower vitamin D pathogenesis (Poddar et al., 2017; Savastano et al., 2017). Vitamin $\mathrm{D}_{3}$ deficiency has also been associated with several types of cancer, although there is still controversy with thyroid cancer (Jonklaas et al., 2013; Kim et al., 2014).

This study's main limitation is related to the number of thyroid nodules diagnosed. Due the small numbers of nodules on control group this study have not enough statistical power to perform multivariable analyses. However, there are previous studies with severe obese patients analyzing the factors associated with the occurrence of thyroid nodules which emphasizes the relevance of our results. Our results for biochemical parameters do not allow inferences on whether they are independent factors associated with thyroid nodules or parameters inherent in obesity itself. Considering the controversy of the subject and the innovative contribution of this study, we stimulate further longitudinal investigations to clarify these questions.

In conclusion, the factors associated with the occurrence of thyroid nodules in severely obese patients were lower age, higher economic level, nonconsumption of alcohol, adiposity, hyperinsulinemia, higher HOMA-IR levels, and lower vitamin $\mathrm{D}_{3}$ levels. These findings contribute to understanding the profile of this specific population and provide an avenue for complementary investigations in the search for independent risk factors for thyroid nodules.

\section{Conflict of Interest}

The authors declare no conflict of interest.

\section{Acknowledgements}

The authors would like to thank the Clinical Research Unit of the Clinical Hospital/Federal University of Goiás and its technical staff for lending us the facilities to conduct this research and for providing technical support. The present work was partially funded by Fundação de Amparo à Pesquisa do Estado de Goiás (FAPEG) grant number 201310267000003. Furthermore, the authors are grateful to all persons who participated in the study. Moreover, To the IF Goiano for the support.

\section{References}

Cappelli C, Pirola I, Mittempergher F, et al (2012). Morbid obesity in women is associated to a lower prevalence of thyroid nodules. Obesity Surg, 22, 460-4.

Dauksiene D, Petkeviciene J, Klumbiene J, et al (2017). Factors associated with the prevalence of thyroid nodules and goiter in middle-aged euthyroid subjects. Int J Endocrinol, 2017, 8401518.

Davies L, Morris LG, Haymart M, et al (2015). American Association of Clinical Endocrinologists and American College of Endocrinology disease state clinical review: the increasing incidence of thyroid cancer. Endocr Pract, 21, 686-96.

Díez JJ, Iglesias P (2011). Relationship between thyrotropin and body mass index in euthyroid subjects. Exp Clin Endocrinol Diabetes, 119, 144-50.

Figueiredo W (2005). Assistência à saúde dos homens: um desafio para os serviços de atenção primária. Ciênc Saúde Coletiva, 10, 105-9.

Guth S, Theune U, Aberle J, Galach A, Bamberger CM (2009). Very high prevalence of thyroid nodules detected by high frequency $(13 \mathrm{MHz})$ ultrasound examination. Eur J Clin Invest, 39, 699-706.

Haugen BR, Alexander EK, Bible KC, et al (2016). 2015 American Thyroid Association management guidelines for adult patients with thyroid nodules and differentiated thyroid cancer: the American Thyroid Association guidelines task force on thyroid nodules and differentiated thyroid cancer. Thyroid, 26, 1-133.

Hegedus L (2004). Clinical practice. The thyroid nodule. NEngl J Med, 351, 1764-71.

Jonklaas J, Danielsen M, Wang H (2013). A pilot study of serum selenium, vitamin $\mathrm{D}$, and thyrotropin concentrations in patients with thyroid cancer. Thyroid, 23, 1079-86.

Kim DL, Song KH, Kim SK (2008). High prevalence of 
carcinoma in ultrasonography-guided fine needle aspiration cytology of thyroid nodules. Endocr J, 55, 135-42.

Kim JR, Kim BH, Kim SM,et al (2014). Low serum 25 hydroxyvitamin $\mathrm{D}$ is associated with poor clinicopathologic characteristics in female patients with papillary thyroid cancer. Thyroid, 24, 1618-24.

Kitahara CM, Platz EA, Ladenson PW, et al (2012). Body fatness and markers of thyroid function among US men and women. PLoS One, 7, e34979.

Knudsen N, Laurberg P, Rasmussen LB, et al (2005). Small differences in thyroid function may be important for body mass index and the occurrence of obesity in the population. $J$ Clin Endocrinol Metab, 90, 4019-24.

Lauby-Secretan B, Scoccianti C, Loomis D, et al (2016). Body fatness and cancer-viewpoint of the IARC Working Group. N Engl J Med, 375, 794-8.

Li HX, Zhang F, Zhao D, et al (2014). Neck circumference as a measure of neck fat and abdominal visceral fat in Chinese adults. BMC Public Health, 14, 311.

NCD Risk Factor Collaboration (NCD-RisC) (2016). Trends in adult body-mass index in 200 countries from 1975 to 2014: a pooled analysis of 1,698 population-based measurement studies with 19.2 million participants. Lancet, 387, 1377-96.

Panagiotou G, Komninou D, Anagnostis P, et al (2017). Association between lifestyle and anthropometric parameters and thyroid nodule features. Endocrine, 56, 560-7.

Papini E, Guglielmi R, Bianchini A, et al (2002). Risk of malignancy in nonpalpable thyroid nodules: predictive value of ultrasound and color-Doppler features. J Clin Endocrinol Metab, 87, 1941-6.

Pappa T, Alevizaki M (2014). Obesity and thyroid cancer: a clinical update. Thyroid, 24, 190-9.

Poddar M, Chetty Y, Chetty VT (2017). How does obesity affect the endocrine system? A narrative review. Clin Obes, 7, 136-44.

Reinehr T (2011). Thyroid function in the nutritionally obese child and adolescent. Curr Opin Pediatr, 23, 415-20.

Rezzonico JN, Rezzonico M, Pusiol E, Pitoia F, Niepomniszcze $\mathrm{H}$ (2008). Introducing the thyroid gland as another victim of the insulin resistance syndrome. Thyroid, 18, 461-4.

Rezzonico JN, Rezzonico M, Pusiol E, Pitoia F, Niepomniszcze $H$ (2009). Increased prevalence of insulin resistance in patients with differentiated thyroid carcinoma. Metab Syndr Relat Disord, 7, 375-80.

Rodrigues AP, Rosa LP, Silveira EA (2018). PPARG2 Pro12Ala polymorphism influences body composition changes in severely obese patients consuming extra virgin olive oil: a randomized clinical trial. Nutr Metab, 15, 2018.

Rotondi M, Leporati P, La Manna A, et al (2009). Raised serum TSH levels in patients with morbid obesity: is it enough to diagnose subclinical hypothyroidism?. Eur J Endocrinol, 160, 403-8.

Ruhla S, Weickert MO, Arafat AM, et al (2010). A high normal $\mathrm{TSH}$ is associated with the metabolic syndrome. Clin Endocrinol (Oxf), 72, 696-701.

Savastano S, Barrea L, Savanelli MC, et al (2017). Low vitamin D status and obesity: role of nutritionist. Rev Endocr Metab Disord, 18, 215-25.

Schmid D, Ricci C, Behrens G, Leitzmann MF (2015). Adiposity and risk of thyroid cancer: a systematic review and meta-analysis. Obes Rev, 16, 1042-54.

Solanki A, Bansal S, Jindal S, Saxena V, Shukla US (2013). Relationship of serum thyroid stimulating hormone with body mass index in healthy adults. Indian $J$ Endocrinol Metab, 17, 167-9.

Sousa PA, Vaisman M, Carneiro JR, et al (2013). Prevalence of goiter and thyroid nodular disease in patients with class III obesity. Arq Bras Endocrinol Metabol, 57, 120-5.

Tan GH, Gharib H (1997). Thyroid incidentalomas: management approaches to nonpalpable nodules discovered incidentally on thyroid imaging. Ann Intern Med, 126, 226-31.

Tolstrup JS, Heitmann B, Tjønneland AM, et al (2005). The relation between drinking pattern and body mass index and waist and hip circumference. Int J Obes (Lond), 29, 490-7.

Ugur KS, Ark N, Kurtaran H, et al (2011). Subcutaneous fat tissue thickness of the anterior neck and umbilicus in patients with obstructive sleep apnea. Otolaryngol Head Neck Surg, 145, 505-10.

Valdés S, Maldonado-Araque C, Lago-Sampedro A, et al (2017). Reference values for TSH may be inadequate to define hypothyroidism in persons with morbid obesity: Diabetes study. Obesity, 25, 788-93.

World Health Organization (WHO) (2000). Obesity: preventing and managing the global epidemic. A report of a WHO consultation. WHO, Geneva.

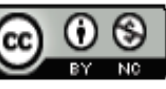

This work is licensed under a Creative Commons AttributionNon Commercial 4.0 International License. 